\title{
The Prediction of Distribution Characteristics of the In-situ Stress for Liuhuanggou Mine Field
}

\author{
Shi yongkui Ding yonglu Wang xiaomeng Xu mingwei \\ Shandong University of Science and Technology \\ 266590, China
}

\begin{abstract}
- he distribution characteristics of the in-situ stress for the mining area of Liuhuanggou mine field was tested by using the stress relief method.The value of the in-situ stress of the non-exploited region was predicted by using the theoretic analysis method and the advice of roadway layout was put forward.
\end{abstract}

Keywords - Prediction ; In-situ stress; Roadway Layout

\section{INTRODUCTION}

Liuhuanggou coal mine is situated at the foot of Tianshan Mountain in Xinjiang,China. The mine field is situated in South wing of the Akord syncline .The strata lean towards northwest which is a monoclonal structure, going from NE to SW.The angle of coal-bearing strata is about $17^{\circ} \sim 19^{\circ}$. There are 18 coal-strata and the coal seams of No.4-5,7and 9-15 are the mining coal seam.And the aggregate thickness is 35.75 $46.33 \mathrm{~m}$ and the average is $41.66 \mathrm{~m}$.Geologic feature of the mining coal seam and the lithologies of roof and floor is shown in table 1.To make the roadway layout and support design more reasonable,the in-situ stress was measured in the mining area and the distribution rules of the in-situ stress of the non-exploited region was predicted

\section{IN-SITU STRESS MEASUREMENT}

The task on the in-situ stress measurement started from 15 September, 2009 to 30 September , 2009. The number of insitu stress spots which was finished was 2.In-situ stress was measured by drilling overcoring stress relief method. And the CSIRO HI sensor which was manufactured by the Australian SCT company was adopted.In addition, the data was tested and analyzed.

TABLE 1 :Geologic Histogram

\begin{tabular}{|c|c|c|}
\hline NO. & Rock property & Rock thickness $/ \boldsymbol{m}$ \\
\hline 1 & sandstone & 49.75 \\
\hline 2 & mudstone & 10.50 \\
\hline 3 & $4-5$ coal seam & 6.15 \\
\hline 4 & siltstone & 2.16 \\
\hline 5 & 7 coal seam & 2.80 \\
\hline 6 & siltstone & 16.63 \\
\hline 7 & $9-15$ coal seam & 30.90 \\
\hline 8 & siltstone & 6.10 \\
\hline \multicolumn{2}{|c}{} \\
\hline
\end{tabular}

The first spot was located in opening position of return air crossheading of $\mathrm{W}$ (4-5)101 rail crossheading.Stress sensor was installed inside the sedimentary rocks. The holes of insitu stress was constructed with an up-angle of $41^{\circ}$ and an azimuth of $320^{\circ}$. The diameter of guide hole was $105 \mathrm{~mm}$ and the length was $10.20 \mathrm{~m}$. The diameter of mounting hole of stress sensor was $38 \mathrm{~mm}$ and length was $0.47 \mathrm{~m}$. The installation depth of the stress sensor was $10.55 \mathrm{~m}$.

The second spot was located in Return Airflow Dip about $5 \mathrm{~m}$ at slope changing points with an elevation of $796 \mathrm{~m}$. The holes of in-situ stress was constructed with an up-angle of $41^{\circ}$ and an azimuth of $50^{\circ}$. The diameter of guide hole was 115 $\mathrm{mm}$ and the length was $10.15 \mathrm{~m}$. The diameter of mounting hole of stress sensor was $38 \mathrm{~mm}$ and length was $0.47 \mathrm{~m}$. The installation depth of the stress sensor was $10.55 \mathrm{~m}$. The test results of the in-situ stress were shown as table 2 .

\section{THE PREDICTION OF IN-SITU STRESS}

A) Estimation method of in-situ stress value near the point of measurement

1) Weight stress field

According

to the principle

of continuous medium mechanics, for the linear elastic and isotropic rock, the weight stress at $h$ meters below surface without load can be calculated by the formula with considering

$\sigma_{z}=r h \sigma_{x}=\sigma_{y}=\frac{\mu}{1-\mu} \sigma_{z}$

Where , $\sigma_{x}$ and $\sigma_{y}$ is the component of horizontal weight stress,$\sigma_{z}$ is the component of vertical weight stress ; $\mu$ is the Poisson's ratio of rock mass.

In the weight stress field, rock mass is in the elastic state and the stress is small in shallow rock mass. The value of stress in the rock mass goes up as the depth goes down.The rock mass changes the state from elastic to latent plasticity when the depth gets to a certain value. And this depth value is the critical depth $H_{c r}$.

The stress component can be calculated by the formula (1) at the critical depth;

$$
\sigma_{z}=\gamma H_{c r} \sigma_{x}=\sigma_{y}=\frac{\mu}{1-\mu} \gamma H_{c r}
$$


TABLE 2: The Test Results Of The In-Situ Stress

\begin{tabular}{|c|c|c|c|c|c|c|c|}
\hline \multicolumn{2}{|c|}{ spot } & $\sigma_{\max }$ & $\sigma_{\text {mid }}$ & $\sigma_{\min }$ & $\sigma_{y}$ & $\sigma_{\max } / \sigma_{m i d}$ & $\sigma_{m i d} / \sigma_{\min }$ \\
\hline \multirow{3}{*}{ The first spot } & size/MPa & 7.32 & 5.83 & 3.20 & 5.86 & \multirow{3}{*}{1.23} & \multirow{3}{*}{1.82} \\
\hline & $\operatorname{dip} /{ }^{\circ}$ & 63.9 & 3.6 & 25.8 & & & \\
\hline & azimuth/ ${ }^{\circ}$ & 336.4 & 238.9 & 147.1 & & & \\
\hline \multirow{3}{*}{$\begin{array}{c}\text { The second } \\
\text { spot }\end{array}$} & size/MPa & 7.44 & 4.72 & 3.50 & 6.74 & \multirow{3}{*}{1.58} & \multirow{3}{*}{1.35} \\
\hline & $\operatorname{dip} /{ }^{\circ}$ & 62.9 & 17.7 & 19.8 & & & \\
\hline & azimuth ${ }^{\circ}$ & 351.6 & 222.9 & 126.3 & & & \\
\hline
\end{tabular}

At the critical depth, the status of stress should base on the yield criterion of rock mass - Hoek-Brown criterion. So

$\sigma_{1}=\sigma_{3}+\sqrt{m \sigma_{c} \sigma_{3}+s \sigma_{c}^{2}}$

According to the formula $\sigma_{z}=\sigma_{1}, \sigma_{x}=\sigma_{y}=\sigma_{3}$, we can get a expression of $H_{c r}$ when the formula (2) is used in the formula (3).

$H_{c r}=\frac{\lambda m+\sqrt{(m \lambda)^{2}+4 s(1-\lambda)^{2}}}{2 \gamma(1-\lambda)^{2}} \cdot \sigma_{c}$

Where, $m$ and $S$ are the constant of rock nature,relating to the rock mass structure and can be referred relevant literature ;

$\sigma_{c}$ is the uniaxial compressive strength of rock block, $M P_{a}$;

$\gamma$ is the average weight density of soil for overlying strata, $M N / m^{3}, \gamma=0.020$ soil on value overlying strata ,$\gamma=0.027$ rock mass on Overlying Strata, $\gamma=0.025$ overlying strata.

$\lambda$ is side pressure coefficient, $\lambda=\frac{\mu}{1-\mu}$

Assuming that the rock mass is an ideal elasticplasticity body, so the stress in rock stratum can be calculated by the formula (4) when the critical depth is more than the depth of $H_{c r}$, and so :

$$
\begin{aligned}
& \sigma_{z}=r h \\
& \sigma_{x}=\sigma_{y}=\sigma_{z}+\frac{1}{2} m \sigma_{c}-\sqrt{m \sigma_{c} \sigma_{z}+\frac{1}{4} m^{2} \sigma_{c}^{2}+s \sigma_{c}^{2}} \\
& \left(h>H_{c r}\right)
\end{aligned}
$$

\section{2) Tectonic stress field \\ 1) elastic state}

When the tectonic stress is small, all strata are in normal elastic state.Because the rock is isotropic, the expression of the in-situ stress in the rock strata was simplified as

$$
\begin{aligned}
& \sigma_{v}=r h \\
& \sigma_{H}=\lambda \sigma_{v}+\sigma_{T}=\frac{v}{1-v} \sigma_{v}+\sigma_{T} \\
& \sigma_{h}=\lambda \sigma_{v}+\lambda \sigma_{T}=\lambda\left(\sigma_{v}+\sigma_{T}\right)
\end{aligned}
$$

$\sigma_{v}$ is the horizontal direction stress ,it is approximately equal to $r h$ in the tectonic stress field, showed according to the experiment results at home and abroad ;

$\sigma_{H}$ is the horizontal maximum stresses, $\sigma_{h}$ is the horizontal minimum stresses ;

$\lambda$ is lateral pressure coefficient ;

$\sigma_{T}$ is horizontal tectonic stress.

(2) elastic-plastic state

In the construction of the stress field of mining area, when $\sigma_{T}$ is large enough,soft rock maybe enter into the natural plastic state, but its deep part is still in elastic state. Therefore, the stress calculation method of the shallow stress(plastic) and the deep stress(elastic) should be different which will be calculated separately.

$\sigma_{1}$ and $\sigma_{2}$ is in the horizontal direction, $\sigma_{3}$ is in the vertical direction. so

$$
\begin{aligned}
& \sigma_{3}=r H_{c r} \\
& \sigma_{1}=r \sigma_{3}+\sigma_{T}
\end{aligned}
$$

Meanwhile, stress at this point should be calculated according to Hoek-Brown criterion which is the formula (3). When formula (7) is used in formula (3), the calculation formula of $H_{c r}$ can be obtained.

$H_{c r}=\frac{1}{\gamma} \frac{2 \sigma_{T}(1-\lambda)+m \sigma_{c}-\sqrt{\left[2 \sigma_{T}(1-\lambda)+m \sigma_{c}\right]^{2}-4(1-\lambda)^{2}\left(\sigma_{T}{ }^{2}-\mathrm{s} \sigma_{c}{ }^{2}\right)}}{2(1-\lambda)^{2}}$

The condition of $H_{c r}=0$ can be obtained by formula (8); 


$$
2 \sigma_{T}(1-\lambda)+m \sigma_{c}=\sqrt{\left[2 \sigma_{T}(1-\lambda)+m \sigma_{c}\right]^{2}-4(1-\lambda)^{2}\left(\sigma_{T}{ }^{2}-\mathrm{s} \sigma_{c}{ }^{2}\right)}
$$

So

$$
\begin{aligned}
& 4(1-\lambda)^{2}\left(\sigma_{T}{ }^{2}-s \sigma_{c}^{2}\right)=0 \\
& \sigma_{T}=\sqrt{s} \sigma_{c}
\end{aligned}
$$

Rock mass is elastic when $\sigma_{T}\left\langle\sqrt{s} \sigma_{c}\right.$, stress in rock strata can be calculated by the formula (6), when $\sigma_{T}=\sqrt{s} \sigma_{c}$, rock mass enter into critical state which is from elastic state into the plastic state, and the depth of plastic zone is zero(on the surface).When $\left.\sigma_{T}\right\rangle \sqrt{s} \sigma_{c}$, if the shallow rock mass entered into plastic yield, firstly, the depth of the plastic zone should be calculated by the formula (8).If the depth of the rock is more than the depth of $H_{c r}$, the rock stress should be calculated according to the formula (6).If the depth of the rock is less than the depth of $H_{c r}$, the rock stress should be calculated according to the following formula(assuming the rock mass as an ideal elastic-plastic material ) :

$$
\begin{aligned}
& \sigma_{1}=\lambda \sigma_{3}+\sigma_{T} \quad \sigma_{3}=r h \\
& \sigma_{1}=\sigma_{3}+\sqrt{m \sigma_{c} \sigma_{3}+s \sigma_{c}^{2}} \\
& \sigma_{2}=\lambda\left(\sigma_{3}+\sigma_{T}\right)
\end{aligned}
$$

When the formula of in-situ stress is deducted as above, the rock is considered as isotropic, and the formula is suitable for both the approximately level strata and nearly vertical layered strata, but $r$ and $\lambda$ should be changed and the particular way is same as the station of self-weight stress field type.

When estimating the value of the rock in-situ stress in type tectonic stress field, the key is to calculate the tectonic stress $\sigma_{T}$ which can only be gotten by measuring the stress of a little bit hard strata. If the stress of the hard rock strata in the mining area has been measured, the stress of other stratas (to be estimated strata) can be obtained in a simple way as following and nearly horizontal layered elastic rocks and nearly vertical layered rocks which to be discussed are divided into two cases .

The elastics modulus of hard strata $E_{1}$, Poisson ratio $E_{2}$ and the measured stress $\sigma_{H 1}, \sigma_{h 1}, \sigma_{v 1}$ are known, and the rock elastic modulus $E_{2}$ and Poisson ratio $\mu_{2}$ of rock in-situ stress are calculated. The strata is assumed as elastic rock strata.

For the approximately level strata,then:

$$
\begin{aligned}
& \varepsilon_{1}=\frac{1}{E_{1}}\left[\sigma_{H 1}-v_{1}\left(\sigma_{h 1}+\sigma_{v 1}\right)\right] \\
& \varepsilon_{2}=\frac{1}{E_{2}}\left[\sigma_{H 2}-v_{2}\left(\sigma_{h 2}+\sigma_{v 2}\right)\right]
\end{aligned}
$$

The strata in a small plot of the same mine which can be approximately regarded that they have the same tectonic deformation, that is $\varepsilon_{1}=\varepsilon_{2}$, then

$$
\frac{E_{1}}{E_{2}}=\frac{\sigma_{H 1}-v_{1}\left(\sigma_{h 1}+\sigma_{v 1}\right)}{\sigma_{H 2}-v_{2}\left(\sigma_{h 2}+\sigma_{v 2}\right)}
$$

At the same time we can get that

$$
\begin{aligned}
& \sigma_{v 2}=\gamma_{2} h_{2} \\
& \sigma_{H 2}=\sigma_{T 2}+\frac{v_{2}}{1-v_{2}} \sigma_{v 2} \\
& \sigma_{h 2}=\frac{v_{2}}{1-v_{2}}\left(\sigma_{v 2}+\sigma_{T 2}\right)
\end{aligned}
$$

There are four unknown numbers $\sigma_{v 2}, \sigma_{H 2}, \sigma_{h 2}, \sigma_{T 2}$ as well as four equations(12)-(15), thus they can be solved. In this way, the in-situ stress value of soft rock and other strata can be calculated according to the measured in-situ stress value of the hard rock strata.

\section{B) Estimation method of in-situ stress value near the point of measurement}

The in-situ stress at an elevation of $696 \mathrm{~m}$ (below the second spot about $100 \mathrm{~m}$ ) can be estimated by the in-situ stress of 2 spots which has been measured.

At an elevation of $696 \mathrm{~m}$, the elastic modulus and Poisson's ratio of the rock are estimated by the elastic modulus of rock mass at the measuring spots. $E=12 \mathrm{GPa}, \quad v=0.31$.

According to the experimental results, $\sigma_{1}>\sigma_{v}$ in both the two measured spots, therefore, it can be seen that the type of Liuhuanggou coal mine is the tectonic stress field.The in-situ stress at an elevation of $696 \mathrm{~m}$ of Liuhuanggou coal mine is estimated by the first spot and the second spot. The results are as follows:

The data is used in the formula (12)-(15) by the first spot ,thus we can get:

$$
\left\{\begin{array}{l}
\frac{14}{12}=\frac{7.19-0.33(3.20+5.86)}{\sigma_{H 2}-0.28\left(\sigma_{h 2}+\sigma_{v 2}\right)} \\
\sigma_{v 2}=0.025 \times(1160-696) \\
\sigma_{H 2}=\sigma_{T 2}+\frac{0.28}{1-0.28} \cdot \sigma_{v 2} \\
\sigma_{h 2}=\frac{0.28}{1-0.28} \cdot\left(\sigma_{v 2}+\sigma_{T 2}\right)
\end{array}\right.
$$

Solution of the above equations, $\sigma_{v 2}=11.6, \sigma_{T 2}=4$, $\sigma_{H 2}=8.5, \quad \sigma_{h 2}=6$.

Due to $\sigma_{T 2}=4, \sqrt{s} \sigma_{c}=28 \times 0.3=8.4, \quad \sigma_{T 2}<\sqrt{s} \sigma_{c}$, the rock mass is elastic. The stress in the rock strata can be calculated by formula (6), thus the values of in-situ stress at an 
elevation

of

696

$\mathrm{m}$

are

$\sigma_{v 2}=11.6, \quad \sigma_{T 2}=4, \sigma_{H 2}=8.5, \sigma_{h 2}=6$.

Based on the same equations, the values of in-situ stress at the elevation $696 \mathrm{~m}$ are estimated by the second spot are: $\sigma_{v 2}=11.6, \sigma_{T 2}=4.356, \sigma_{H 2}=8.856, \sigma_{h 2}=6.199$.

Finally, the weighted mean of the two estimated values are regarded as the final estimated value of in-situ stress. The elevation of the second spot is closer to the point estimated (at an elevation of $696 \mathrm{~m}$ ), so the weight of in-situ stress value is 6 and the weight coefficient is $\frac{3}{5}$. The weight of in-situ stress value which is calculated by the first spot is 4 and the weight coefficient is $\frac{2}{5} \cdot \sigma=\frac{2}{5} \sigma_{1}+\frac{3}{5} \sigma_{2}\left(\sigma_{1}\right.$ is the value of in-situ stress which is calculated by the first spot, $\sigma_{2}$ is the value of in-situ stress which is calculated by the second spot )

The final value of in-situ stress at the elevation of $696 \mathrm{~m}$ are: $\sigma_{v 2}=11.6, \sigma_{T 2}=4.2, \sigma_{H 2}=8.7, \sigma_{h 2}=6.1$.

\section{SugGestions ON THE ARRAngEMENT OF Mining AREA} TUNNEL

The crossheading strike of the working face of $\mathrm{W}$ (9-15) 102 is $235^{\circ}$ which consistent with the direction of the maximum horizontal principal stress force, but the open-off cut is vertical with that. In practice, it is found that the bursts occurred frequently during tunneling the crosseheading and the open-off cut, especially during tunneling the open-off cut.Due to the roadway under high pressure, the roof broke easily and is difficult to be controlled.

Based on the test results of in-situ stress, it is suggested that when arranging the roadway, the azimuth angle of the roadway is controlled as far as possible between $220^{\circ} \sim 250^{\circ}$.

\section{REFERENCES}

[1]Meng Xiangrui,XU Chenghui,Gao Zhaoning,et al.Stress distribution and damage mechanism of mining floor[J].Journal of China Coal Society,2010,35(11):1832-1836.

[2]Zhang Pingsong,Hu Xiongwu,Liu Shengdong.Study of dynamic detection simulation of overburden failure in model workface [J].Chinese Journal of Rock Mechanics and Engineering,2011,30(1) :78-83.

[3]Pal CHIK V,HATZOR Y H.Correlation between mechanical strength and microstructural parameters of dolomites and limestones in the Judea group [J].Israel Journal of Earth Sciences,2000,49(2):65-79.

[4]MAZULLO S J,CHILINGARIAN G V,BISSELL H J.Carbonate rock classification.carbonate reservoirs characterization:a geological engineering analysis(Part 1)[M].Amsterdam:Elsevier, 1992:59-108.

[5]Zhou Songjiang.Study of extremely close position distance coal seam mining road[J].Problem Discussion,2011,20(7):42-50. 